УДК 611.146.4

DOI: 10.26435/UC.V0I4(33).371

\author{
В.А. Васильев, О.А. Бешуля, Е.С. Селиванова
}

ГОО ВПО «Донецкий национальный медицинский университет имени М. Горького», Донецк

\title{
ВАРИАНТНАЯ АНАТОМИЯ ПЕЧЕНОЧНЫХ ВЕН
}

В течение последних десятилетий особое внимание уделяется вопросу изучения ангиоархитектоники печени. В отечественной и зарубежной литературе описывается вариабельность индивидуальной сосудистой анатомии печени с точки зрения ее применения в таких областях медицины, как трансплантология, гепатобиллиарная хирургия, лучевая диагностика, ведь именно на этом основана функциональная анатомия печени. Знание сосудистой анатомии печени позволяет оценить особенности кровоснабжения органа, во многом определяет тактику и методику проведения хирургических манипуляций, дает возможность проводить оценку вариантов сосудистой реконструкции.

Много работ посвящено изучению печеночных вен, так как именно их строение имеет противоречивое описание в научной литературе. Знание анатомии печеночных вен, а также нижней полой вены (НПВ) обязательно для более детального изучения аспектов сегментарной резекции печени, трансплантации и лечении травм с разрывом печеночных вен $[1,2]$. Исследования, посвященные этому вопросу, основаны на материалах, которые содержат достаточно разрозненные данные и отличаются существенным информационным многообразием. Это связано с этнической принадлежностью исследуемых, применением авторами различных методов, использованием модифицированных классификаций.

Кровообращение печени уникально. Оно осуществляется печеночной артерией (обеспечивает от $25 \%$ до $30 \%$ кровоснабжения со скоростью 400 миллилитров в минуту) и воротной веной (до 75-80\% крови). Это кровь от поджелудочной железы, селезенки, толстой и тонкой кишки. В целом за одну минуту через печень проходит 1,5 л крови, что составляет 25\% минутного объема всего кровообращения [3].

Классическая анатомия печеночных вен первоначально описана в классификации Soyer (1995). Печеночные вены являются эфферентными сосудами печени и располагаются внутриорганно. Это тонкостенные анэхогенные со- суды, не имеющие клапанов. Впервые они были описаны Glisson (1654): он обнаружил три крупные вены и большое количество вен меньшего размера, которые также впадали в НПВ. Отчетливо три печеночные вены определяются с 4-го месяца внутриутробного развития. Распределение печеночных вен в эмбрионах человека напоминает распределение их в уже сформировавшемся зрелом организме. [4]. Диаметр печеночных вен значительно изменяется с возрастом. Так как у детей первых трех лет жизни левая доля печени по размерам достаточно большая, то в этом возрастном периоде левая печеночная вена и средняя печеночная вена больше в диаметре, чем правая. Затем соотношение диаметров меняется в сторону правой печеночной вены (ее диаметр у взрослого человека больше, чем левой и средних печеночных вен) [5].

В норме численность печеночных вен, имеющих отдельные стволы, находится в диапазоне от 3 до 25, в некоторых исследованиях даже больше [5]. Сборные вены формируют три основные, встречающиеся почти у всех людей: правую (ППВ), среднюю (СПВ) и левую печеночные вены (ЛПВ), впадающие в НПВ [5-7]. Расстояние от верхней печеночной вены до места, где НПВ проходит через одноименное диафрагмальное отверстие, - от 4 до 11 мм. Часть НПВ, где открываются печеночные вены, находится на висцеральной поверхности в борозде НПВ. Она проходит через голое поле печени. Между стенкой НПВ и бороздой имеется едва заметная прослойка соединительной ткани, через которую проходят концевые отделы мелких нижних печеночных вен. Отдел НПВ на уровне впадения печеночных вен принято называть кавальными, или вторыми воротами печени $[5,8]$.

Печеночные вены можно разделить на две группы - верхнюю и нижнюю. Нижняя группа выходит из правой и хвостатой доли печени и насчитывает от 2 до 6 сосудов. Верхняя группа выходит из квадратной и левой долей на висце-

(c) В.А. Васильев, О.А. Бешуля, Е.С. Селиванова, 2019

(C) Университетская Клиника, 2019 
ральной поверхности печени. В верхней группе классически есть три печеночные вены, и они больше по диаметру, чем вены верхней группы [5]. Долгие годы анатомические варианты формирования и впадения ЛПВ и СПВ в НПВ вызывали дебаты между учеными. В 2004 году авторами S. Orguc и M. Tercan была модифицирована схема Soyer. Они дали более простое и на сегодняшний день самое используемое описание печеночных вен. Согласно этой классификации описываются следующие анатомические варианты ЛПВ:

1. ЛПВ имеет одиночный ствол (16\%).

2. Передняя и задняя ветви ЛПВ отдельно впадают в НПВ.

3. Формирование слияния передней и задней ветвей ЛПВ с образованием общего ствола.

4. Слияние передней и задней ветвей ЛПВ с образованием общего ствола с присоединением латеральной ветви от IV сегмента.

Отток венозной крови из печени обусловлен величиной угла, образующегося при впадении той или иной печеночной вены в НПВ. С этой точки зрения угол впадения ППВ в НПВ (от 35 до $40^{\circ}$ ) обеспечивает более подходящие условия для кровообращения, чем ЛПВ (60-90). На угол впадения печеночных вен в НПВ влияет топографическое положение печени и непосредственно внутрипеченочного отдела нижней полой вены. Например, при вентролатеральном положении печени угол более острый, при дорсопетальном - приближается к 90 [9].

Углубленное изучение топографии печеночных вен показало неточность имеющихся представлений о распределении печеночных вен в органе. Именно поэтому их визуализация при ультразвуковом исследовании может быть выполнена с четырех различных позиций. Рассматривается вариант с позиции брюшной части пищевода, начального отдела двенадцатиперстной кишки и тела желудка.

Печеночные вены обеспечивают отток крови от сегментов печени. История анатомической сегментации органа началась в конце 15-го века с морфологических наблюдений за ее внешней формой и видоизменялась в течение 300-400 лет в векторе современной концепции сегментации печени: Rex (1888), Cantlie (1898) и Serege (1901) выделили в печени правую и левую доли, в 1888 году Rex отстаивал концепцию, основанную на анатомии портальной системы. Cantlie, независимо от него, обнаружил те же анатомические характеристики печени и описал клиническое применение этих сегментарных характеристик $[1,5,10]$.

По классификации Куино, печень подразделяют на правую и левую доли, пять отдельных секторов и восемь сегментов. Хвостатой доле принадлежит первый сегмент; второй и третий сегменты выделяют слева от ЛПВ и серповидной связки, четвертый находится между ЛПВ и СПВ и делится на $4 \mathrm{a}$ и 4b подсегменты в пределах квадратной доли печени; пятый сегмент - между СПВ и ППВ; шестой - ниже воротной вены, справа и кзади от ППВ; седьмой справа от ППВ; восьмой сегмент имеет границы выше уровня воротной вены между СПВ и ППВ [10]. Таким образом, печеночные вены разделяют сегменты в аксиальной плоскости: $2 / 3,4 \mathrm{a} / 4 \mathrm{~b}$, $8 / 5,7 / 6$. Но при этом как границы сегмента, так и их количество остаются противоречивыми из-за неполного понимания роли долей печени и физиологии сосудов в развитии венозной печени.

Также используют схему деления воротной и печеночной вен («французская» модель) или желчных протоков («американская» модель) в качестве критериев сегментации. Сходство сегментарных границ французской и американской моделей предполагает, что в основе сегментарной анатомии печени лежит адаптивный механизм, например, вызванной перфузией и метаболическими потребностями. В зарубежных источниках принято использовать номенклатуру «Brisbane 2000», модифицированную Bismuth (2013).

Согласно классификации Couinand определены соответствующие разновидности образования вен печени: собственная вена четвертого сегмента, в $12,5 \%$ случаев впадающая в место слияния ЛПВ и СПВ; вена шестого и второго сегмента, которая впадает в НПВ (2,5\%); две ЛПВ от второго и третьего сегментов (19\%); из четвертого сегмента кровь оттекает в СПВ (13\%).

В литературе имеются сведения относительно следующих вариантов формирования печеночных вен: отток крови из VI и VII сегментов - ППВ, в СПВ - из IV, V и VIII сегментов, а в ЛПВ - из II и III сегментов. Отток крови из I сегмента происходит по двум мелким венам в НПВ у места, где она входит непосредственно в печень. Основная печеночная вена хвостатой доли превращается во внутрипеченочную часть НПВ. Этот факт объясняет, почему часто несколько относительно небольших печеночных вен из хвостатой доли стекают прямо в НПВ. Кроме главной ППВ, выделяют еще от двух до четырех мелких вен, по которым собирается кровь из VI и VII сегментов. [12]

В зарубежной литературе чаще всего встречаются данные о том, что ЛПВ дренирует сегменты II и III, СПВ - сегменты IV, V и VIII, ППВ - сегменты V-VII. Приблизительно у 60\% населения средние и левые печеночные вены соединяются, чтобы сформировать общий ствол, сте- 
кающий отдельно в НПВ [11]. ЛПВ обеспечивает отток крови от сегментов II, III, IVa и IVb. При этом доминантной веной (60-78\%) считают ППВ и отмечают ее раннюю бифуркацию, трифуркацию или даже множественные правые печеночные вены. [5, 7, 11]

В литературе выделяют промежуточный, рассыпной и магистральный типы строения печеночных вен. Магистральный тип имеет место в 70\% [10]. При рассыпном типе очень сложно выделить основной ствол, вместо него выделяют 2-3 вены приблизительно одного диаметра [11].

Вариабельность формирования и обеспечения оттока крови от печени описывается авто- рами на основании первичной классификации Soyer (1994).

\section{В Ы В 0 Д b}

1. Наиболее часто встречающееся количество печеночных вен - от трех до пяти.

2. Средняя и левая печеночные вены в $80 \%$ случаев формируют общий ствол, который открывается в нижнюю полую вену рядом с правой печеночной веной.

3. Доминантной веной большинство авторов определяют правую печеночную вену.

4. Преобладающим типом строения печеночных вен является магистральный.

\section{В.А. Васильев, О.А. Бешуля, Е.С. Селиванова}

ГОО ВПО «Донецкий национальный медицинский университет имени М. Горького», Донецк

\section{ВАРИАНТНАЯ АНАТОМИЯ ПЕЧЕНОЧНЫХ ВЕН}

Ангиоархитектоника печени рассматривается с анатомической и хирургической точки зрения с целью формирования представления об особенностях сосудистого русла, параметров и строения сосудов. Печеночные вены, их количество и способы деления имеют высокую вариабельность. В зависимости от их числа, варианта обеспечения оттока крови от сегмен- та печени определяется хирургическая тактика при операциях на печени, именно поэтому изучение системы печеночных вен имеет большое практическое значение для повышения уровня диагностики гепатобиллиарной системы.

Ключевые слова: печень, печеночные вены, нижняя полая вена, гепатобиллиарная система.

\section{V.A.Vasiliev, O.O.Beshulia, E.S.Selivanova}

SEI HPE «M. Gorky Donetsk National Medical University», Donetsk

\section{VARIANT ANATOMY OF HEPATIC VEINS}

Angioarchitecture of the liver is considered from the anatomical and surgical point of view in order to form an idea of the features of the vascular bed, parameters and structure of blood vessels. Hepatic veins, their number and division methods have high variability. Depending on their number, the option of ensuring blood outflow from the liver segment the surgical tactic is determined during operations on the liver, that is why the study of the hepatic vein system is of high practical importance and the need to increase the level of diagnosis of the hepatobiliary system.

Key words: liver, hepatic veins, inferior vena cava, hepatobiliary system.

\section{ЛИТЕРАТУРА}

1. Sakamoto Y., Kokudo N., Kawaguchi Y., Akita K. Clinical Anatomy of the Liver: Review of the 19th Meeting of the Japanese Research Society of Clinical Anatomy. Liver Cancer. 2017; 6: 146-160. doi:10.1159/000449490

2. Jill P.J.M. Hikspoors, Mathijs M.J.P. Peeters, Nutmethee Kruepunga, Hayelom K. Mekonen, Greet M.C. Mommen, S. Eleonore Köhler, Wouter H. Lamers Human liver segments: role of cryptic liver lobes and vascular physiology in the development of liver veins and left-right asymmetry. Scientific Reports. 2017; v. 7, 1: 17109. doi:10.1038/ s41598-017-16840-1

3. Понукалина Е.В., Чеснокова Н.П., Полутова Н.В. Общая характеристика анатомо-физиологических особен-

\section{REFERENCES}

1. Sakamoto Y., Kokudo N., Kawaguchi Y., Akita K. Clinical Anatomy of the Liver: Review of the 19th Meeting of the Japanese Research Society of Clinical Anatomy. Liver Cancer. 2017; 6: 146-160. doi:10.1159/000449490

2. Jill P.J.M. Hikspoors, Mathijs M.J.P. Peeters, Nutmethee Kruepunga, Hayelom K. Mekonen, Greet M.C. Mommen, S. Eleonore Köhler, Wouter H. Lamers Human liver segments: role of cryptic liver lobes and vascular physiology in the development of liver veins and left-right asymmetry. Scientific Reports. 2017; v. 7, 1: 17109. doi:10.1038/ s41598-017-16840-1

3. Ponukalina E.V., Chesnokova N.P., Polutova N.V. Obshchaya kharakteristika anatomo-fiziologicheskikh osobennos- 
ностей печени: иннервация, кровоснабжение, микроморфология и функциональной значимости в организме: материалы международной научно-практической конференции. 4 мая 2019. Уфа; 2019: 166-171.

4. Sozos J. Fasouliotis, Reuven Achiron, Zvi Kivilevitch, Simcha Yagel. The human fetal venous system normal embryologic, anatomic, and physiologic characteristics and developmental abnormalities: J. Ultrasound Med. 2002; 21 (21): 1145-1158.

5. Максименков А.Н. Хирургическая анатомия живота: Руководство для хирургов. М.; 2012.682.

6. Clavien P-A. Atlas of upper gastrointestinal and hepatopancreato-biliary surgery. Berlin: Springer, 2007. 950.

7. Pietro Majno, Gilles Mentha, Christian Toso, Philippe Morel, Heinz O. Peitgen, Jean H.D. Fasel Anatomy of the liver: An outline with three levels of complexity - A further step towards tailored territorial liver resections. Journal of Hepatology. 2014; 60 (3): 654-662. doi: 10.1016/j. jhep.2013.10.026

8. Кованов В.В. Оперативная хирургия и топографическая анатомия. М.: Медицина; 2001. 408.

9. Ahmed A., Baig A.H., Sharif M.A., Ahmed U., Gururajan R. Role of Accessory Right Inferior Hepatic Veins in evaluation of Liver Transplantation. Ann Clin Gastroenterol Hepatol. 2017; 1: 012-016. doi:10.29328/journal.acgh.1001004

10. Catalano O.A., Singh A.H., Uppot R.N., Hahn P.F., Ferrone C.R., Sahani D.V. Vascular and biliary variants in the liver: implications for liver surgery. Radiographics. 2008. 28 (2): 359-378.

11. Баталова Ю.С., Нузова О.Б. Современные лапароскопические технологии при лечении желчнокаменной болезни. Оренбургский медицинский вестник. 2015; 4 (12): 61-67.

12. Борисов А.Е. Руководство по хирургии печени и желчевыводящих путей. СПб.: ЭФА; 2002. 448. tei pecheni: innervatsiya, krovosnabzhenie, mikromorfologiya i funktsional'noi znachimosti v organizme: materialy mezhdunarodnoi nauchno-prakticheskoi konferentsii. 4 maya 2019. Ufa; 2019: 166-171.

4. Sozos J. Fasouliotis, Reuven Achiron, Zvi Kivilevitch, Simcha Yagel. The human fetal venous system normal embryologic, anatomic, and physiologic characteristics and developmental abnormalities: J. Ultrasound Med. 2002; 21 (21): 1145-1158.

5. Maksimenkov A.N. Khirurgicheskaya anatomiya zhivota: Rukovodstvo dlya khirurgov. M.; 2012. 682.

6. Clavien P-A. Atlas of upper gastrointestinal and hepatopancreato-biliary surgery. Berlin: Springer, 2007. 950.

7. Pietro Majno, Gilles Mentha, Christian Toso, Philippe Morel, Heinz O. Peitgen, Jean H.D. Fasel Anatomy of the liver: An outline with three levels of complexity - A further step towards tailored territorial liver resections. Journal of Hepatology. 2014; 60 (3): 654-662. doi: 10.1016/j. jhep.2013.10.026

8. Kovanov V.V. Operativnaya khirurgiya i topograficheskaya anatomiya. M.: Meditsina; 2001. 408.

9. Ahmed A., Baig A.H., Sharif M.A., Ahmed U., Gururajan R. Role of Accessory Right Inferior Hepatic Veins in evaluation of Liver Transplantation. Ann Clin Gastroenterol Hepatol. 2017; 1: 012-016. doi:10.29328/journal.acgh.1001004

10. Catalano O.A., Singh A.H., Uppot R.N., Hahn P.F., Ferrone C.R., Sahani D.V. Vascular and biliary variants in the liver: implications for liver surgery. Radiographics. 2008. 28 (2): 359-378.

11. Batalova Yu.S., Nuzova O.B. Sovremennye laparoskopicheskie tekhnologii pri lechenii zhelchnokamennoi bolezni. Orenburgskii meditsinskii vestnik. 2015; 4 (12): 61-67.

12. Borisov A.E. Rukovodstvo po khirurgii pecheni i zhelchevyvodyashchikh putei. SPb.: EFA; 2002. 448. 